\title{
Facial profile preferences, self-awareness and perception among a sample of university students
}

\author{
Lina S. Ali ${ }^{1}$ and Amal H. Abuaffan ${ }^{2 *}$ \\ ${ }^{1}$ General dentist, University of Medical Science and Technology, Khartoun Sudan \\ ${ }^{2}$ Associate Professor, Department of Orthodontic, University of Medical Science and Technology, Khartoum, Sudan
}

\begin{abstract}
Background: The face is thought to be an important feature in the determination of human physical attractiveness. Individuals with attractive faces tending to be more socially flourishingand friendly in the community.

Objectives: A cross sectional study to assess facial profile preference and self awareness in a sample of Sudanese university students and its correlation between genders.

Material and methods: Total sample of 358 Sudanese students (179 Males and 179 Females), facial profile photographs were taken from each student. To assess differences in facial profile perception, students were asked to rank the profiles using seven different facial profile silhouette for each gender on a series from most to least attractive. Awareness of the facial appearance on a profile view was evaluated using questionnaires fulfilled by the students.

Results: The straight facial profile was evident to be extremely attractive by both males (30.7\%) and females (37.4\%), retruded maxilla followed by a similar result amongst females (37.4\%). The least attractive profiles were the protrusive maxilla (28.5\%) and the bimaxillary protrusion (33.5\%) for the male and the female profiles, respectively. A higher percentage of females (71.5\%) were aware of their facial profile than male participants (51.4\%). A statistically significant difference was found between gender and both facial profile perception and self-awareness ( $p$ value $\leq 0.05$ ).
\end{abstract}

Conclusion: Straight facial profile was chosen to be the most attractive facial profile among both genders. Most of the students correctly perceived their facial profile; thus a strong correlation was found between facial profile preference and self awareness as well as gender.

\section{Introduction}

Modern society places strong emphasis on physical attractiveness and facial beauty. The face is thought to be an important feature in the determination of human physical attractiveness [1]. Over the years there were significant changes in the standard of facial esthetic, so orthodontists must be updated about what the population considers an ideal face [2]. From the patient's point of view, esthetics is the main reason for seeking orthodontic treatment [3].

The profile analysis is important as it can be used as a basis for orthodontic treatment need [4].

Ethnicity had a strong influence on judging facial attractiveness. From a point of view some races consider facial profiles with mandibular retrognathism to be both socially and esthetically acceptable, while other races see otherwise [5-7]. The main reason for seeking orthognathic surgery is improvement of the facial profile appearance [8]. It has been found that most of the populations aren't able to characterize their own profiles; however the level of education possesses a strong perception-affecting factor [9].

Previous methods used to analyze the facial profile; line tracing, silhouettes, facial pictures and slides [10]. Some authors preferred the use of facial photographs to evaluate esthetics, considering that photographs provide more accurate evaluation of measurements and proportion, allow observation of the relationship between soft and hard facial tissues, as well as protecting the patient from radiation and with a low cost [11-13].
Attention to physical appearance, especially of the face, has become a great issue in modern society $[14,15]$. For thousands of years, the study of the face and the ability to change its structure has fascinated the mankind. Soft tissue evaluation which includes the assessment of soft tissue-profile esthetics is a key aspect of orthodontic diagnosis and treatment planning [16]. Studies have been developed in an attempt to define a beautiful face but the definition changes as society and its esthetic values change [17-20].

The concept of facial beauty and profile harmony play a decisive role in social relationships of all people. Therefore, it is intensely studied in scientific research [21].

Today, numerous methods are available for evaluation of facial changes and variations. Facial profile is an important clinical diagnostic tool during the patient's pre-treatment evaluation for dental treatment. This shows that with knowledge of the normal values of soft tissues and dental and skeletal structures, the treatment plan can be directed using various diagnostic tools clinically, taking into consideration family and

Correspondence to: Dr. Amal H. Abuaffan, BDS, MSc. Associate Professor Department of Orthodontic, University of Medical Sciences and Technology, Khartoum, Sudan, Tel: 00249-912696035; E-mail: amalabuaffan@yahoo.com

Keywords: facial profile, preference, self-awareness, sudanesee students

Received: September 07, 2015; Accepted: October 21, 2015; Published: October 24,2015 
ethnic characteristics for a successful orthodontic treatment [22].

To our knowledge Sudanese data concerning facial profiles, their attractiveness and people's perception is not well studied, therefore the present study has been designed to assess this topic and present its relevance in the field of dentistry.

\section{Materials and methods}

This is a cross-section study carried out for a sample of Sudanese university students in the University of Medical Science and Technology from December 2014 to March 2015.

Permission and approval was obtained from the University of Medical Sciences and Technology to carry out the study. An informed and written consent was attained from each participant before taking part in this study, all participants were given brief details about the aim of the study and the methods that will be carried out and were told that their personal data will remain confidential throughout the study. Those who didn't approve of the procedures which will be undertaken were not included. Lists of students from each batch were obtained and a sample of students was randomly selected, those who agreed to participate in the study signed a consent form and later were called to have their photograph taken. The data sheet was filled by each student that fulfilled the inclusion criteria; Sudanese nationality, age range 16-22 years, no facial abnormality and the one who had or in active orthodontic treatment.

The sample size was calculated using the formula below:

$$
\mathrm{n}=\frac{N \cdot Z^{2} \cdot p(1-p)}{\left[\left(N \cdot d^{2}\right)+Z^{2} * p(1-p)\right]}
$$

Whereas: $\mathrm{n}=$ Sample size.

\section{$\mathrm{N}=$ Population size}

$\mathrm{Z}=$ The standard normal deviation at 95\% confident level (1.96).

$\mathrm{P}=$ The proportion in the target population estimated to have a particular characteristic (0.5).

$\mathrm{d}=$ The degree of accuracy or the accepted margin of error (0.05).

Therefore, the sample size are:

$$
\mathrm{n}=\frac{5110 *\left(1.96^{2}\right) * 0.5(1-0.5)}{\left[\left(5110 *(0.05)^{2}\right)+\left((1.96)^{2} * 0.5(1-0.5)\right)\right]}=\text { approx }=358
$$

\section{Facial profile preference}

Figure 1 shows the manipulated profile images used in the study to assess theparticipants facial profile perception. The profiles wereorganized in one row; sidebyside, for each gender; thus allowing equal comparisons to bemade. Moreover, the order of arrangement of profile images for eachgender was different topreventpattern detection [23].

\section{Facial profile self-awareness}

The baseline templates were used to generate images of the three ultimate facial profile types, i.e., straight, convex and concave (Figure 2) [23].

Facial profile pictures were then taken of each subject by the main investigator using (Samsung, 8 Mega pixels Auto Focus with Flash) camera that was later assessed to evaluate degree of self awareness.
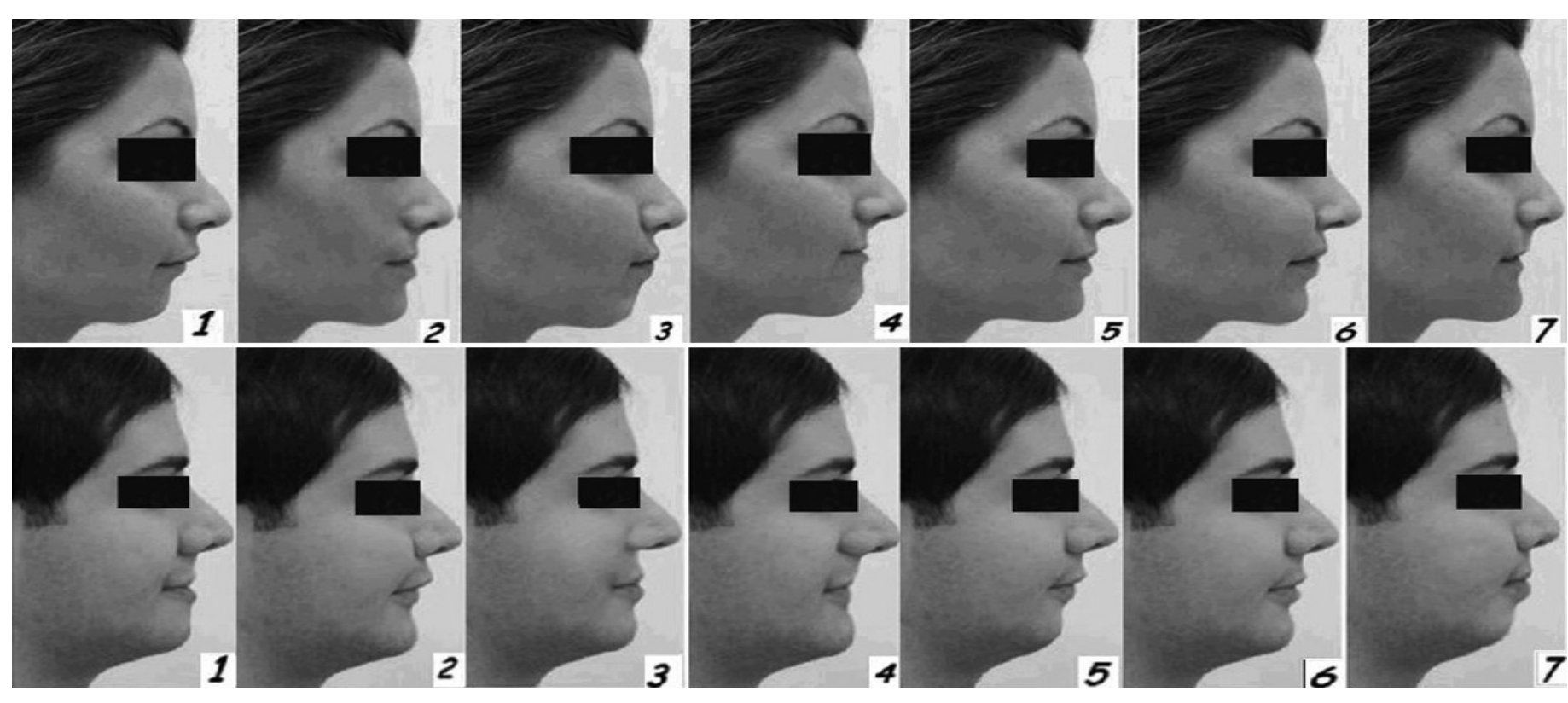

Figure 1. Facial profile silhouettes with varying manipulated anterio-posterior skeletal relationships.

M6 and F5 illustrating the straight profile with no manipulations.

M3 and F2 illustrating the profile with a retruded maxilla.

$\mathrm{M} 5$ and $\mathrm{F} 1$ illustrating mandibular retrognathism.

M1 and F4 illustrating mandibular prognathism.

M2 and F6 illustrating protrusive maxilla.

$\mathrm{M} 7$ and $\mathrm{F} 3$ illustrating the bimaxillary protrusion.

M4 and F7 illustrating the bimaxillaryretrusion. 


\section{Data analysis}

Data was collected, summarized, coded and entered to the Statistical Package for Social Sciences (SPSS) program (version 17) in the computer. The data was analyzed in the form of tables.

Chi square test was used to examine the association between facial profile preference and perception in relation to gender. For all statistical tests a P-value of less than 0.05 was considered to be significant.

\section{Results}

A sample of 358 students 179 male (50.0\%) and 179 female (50.0\%) from the University of Medical science and Technology were participated in this study, their age ranged from 16 to 22 years. All participants were of Sudanese Nationality.

\section{Facial profile preferences}

Table 1 showed that the mean rank scores assigned to each of the male and female facial profile types. The attractiveness score of both the profiles ranged between 1 (highest score) and 7 (least score).The straight profile was chosen by male participants $(30.7 \%)$ to be the most attractive. Whereas, the straight profile and retruded maxilla ranked similar results (37.4\%) as being the most attractive facial profile amongst female participants. A significant different was observed between gender $\mathrm{P}$ value $=0.001$.

Table 2 shows the mean rank score for the least attractive facial profile for both genders. Bimaxillary protrusion was ranked by females $(33.5 \%)$ to be the least attractive facial profile, followed by maxillary

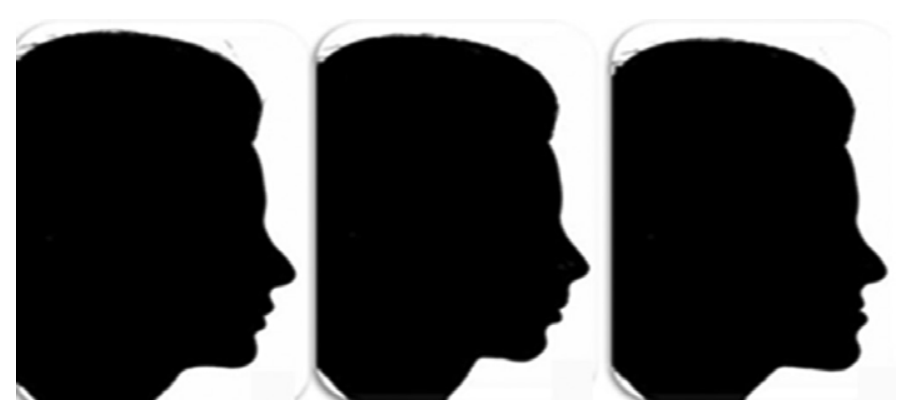

Figure 2. Facial profile self-awareness. protrusion which in turn was found to be the least appealing profile for a male (28.5\%).

Clearly a significant difference was found in the agreement of ranking of the most and least preferred facial profile by all participants.

\section{Facial profile self-awareness}

Table 3 shows that almost half of the male participants correctly perceived their facial profile. In spite of that, females were still the most conscious of their profile types and a much higher percentage correctly perceived their facial profile. Significant differences existed when comparing the awareness of facial profile between genders (P-value $=0.001)$.

\section{Discussion}

This study is a cross sectional carried out among a sample of Sudanese university students to evaluate awareness and attractiveness of the facial profile.

\section{Facial profile preferences}

Orthodontic treatment is usuallydirected towards obtaining a nearly straight facial profile, translating to an angle of $169^{\circ}$ [22]. This treatment intention is further validated by the similarity of perception in our findings; which suggest straight profiles were regarded as the most attractive profiles among both male and female participants.

In the current result males recorded that a female profile with a protrusive maxilla very unattractive, whereas females chose males with bimaxillary protrusion to be the least appealing; a significance difference was reported related to gender.

In contrast Amjad et al. [23] and Sheriann et al. [24] results show that there was nosignificant differences related to age, gender and race. Whereas, Wang Yuan-yuanconcluded that there was no significant difference between male and female patients in facial profile preferences $(\mathrm{P}>0.05)$ and that facial profile preferences are influenced more by age than gender [25].

Similarly Susan et al. reported that gender did not influence attractiveness rankings and the most attractive facial profile is the orthognathic male image with a normal lower anterior facial height and female orthognathic image with a reduced lower anterior facial height among Jordanian population [26].

Table 1. Comparison between the rank of the most attractive facial profile among females and males)

\begin{tabular}{|l|l|l|l|l|l|l|l|}
\hline $\begin{array}{l}\text { Type of facial } \\
\text { profile }\end{array}$ & $\begin{array}{l}\text { straight } \\
\text { profile }\end{array}$ & $\begin{array}{l}\text { retruded } \\
\text { maxilla }\end{array}$ & $\begin{array}{l}\text { mandibular } \\
\text { retrognathism }\end{array}$ & $\begin{array}{l}\text { mandibular } \\
\text { prognathism }\end{array}$ & $\begin{array}{l}\text { protrusive } \\
\text { maxilla }\end{array}$ & $\begin{array}{l}\text { bimaxillary } \\
\text { protrusion }\end{array}$ & $\begin{array}{l}\text { bimaillaryretrusion } \\
\text { Male }\end{array}$ \\
\hline Female & $65(30.7 \%)$ & $43(24.0 \%)$ & $5(2.8 \%)$ & $22(12.3 \%)$ & $35(19.6 \%)$ & $13(7.3 \%)$ & $6(3.4 \%)$ \\
\hline Total & $67(37.4 \%)$ & $67(37.4 \%)$ & $6(3.4 \%)$ & $25(14.0 \%)$ & $8(4.5 \%)$ & $1(0.6 \%)$ & $5(2.8 \%)$ \\
\hline
\end{tabular}

p-value $=(0.001)$

Table 2. Comparison between the ranks of the least attractive facial profile among gender.

\begin{tabular}{|c|c|c|c|c|c|c|c|c|}
\hline \multirow[b]{2}{*}{ Gender } & \multicolumn{7}{|c|}{ Type of facial profile } & \multirow[b]{2}{*}{ Total } \\
\hline & straight profile & $\begin{array}{l}\text { retruded } \\
\text { maxilla }\end{array}$ & $\begin{array}{l}\text { mandibular } \\
\text { retrognathism }\end{array}$ & $\begin{array}{l}\text { mandibular } \\
\text { prognathism }\end{array}$ & $\begin{array}{l}\text { protrusive } \\
\text { maxilla }\end{array}$ & $\begin{array}{c}\text { bimaxillary } \\
\text { protrusion }\end{array}$ & bimaxillaryretrusion & \\
\hline Male & $4(2.2 \%)$ & $16(8.9 \%)$ & $27(15.1 \%)$ & $28(15.6 \%)$ & $51(28.5 \%)$ & $19(10.6 \%)$ & $34(19.0 \%)$ & $179(100.0 \%)$ \\
\hline Female & $0(0.0 \%)$ & $7(3.9 \%)$ & $24(13.4 \%)$ & $15(8.4 \%)$ & $28(15.6 \%)$ & $60(33.5 \%)$ & $45(25.1 \%)$ & $179(100.0 \%)$ \\
\hline Total & $4(1.1 \%)$ & $23(6.4 \%)$ & $51(14.2 \%)$ & $43(12.0 \%)$ & $79(22.1 \%)$ & $79(22.1 \%)$ & $79(22.1 \%)$ & $358(100.0 \%)$ \\
\hline
\end{tabular}

$p$-value $=(0.001)$ 
Table 3. Comparison between perception of facial profile among males and females).

\begin{tabular}{|l|l|l|l|l|}
\hline \multicolumn{2}{|l|}{ Perception } & Right & Wrong & \\
\hline \multirow{2}{*}{ Gender } & Male & $92(51.4 \%)$ & $87(48.6 \%)$ & $179(100.0 \%)$ \\
\cline { 2 - 5 } & Female & $128(71.5 \%)$ & $51(28.5 \%$ & $179(100.0 \%)$ \\
\hline Total & $220(61.5 \%)$ & $138(38.5 \%)$ & $358(100.0 \%)$ \\
\hline
\end{tabular}

In another study Mejia Maidl et al. recorded similar results of insignificance between genders in the preferred female image and male profile images for Caucasians, low-acculturated Mexican Americans, or high-acculturated Mexican Americans [27]. However Amjad et al. concluded that Male facial profiles with bimaxillary protrusion and a female profile with retruded mandible were considered the least attractive in a study among the population of United Arab Emirates while both genders chose the straight profile to be the most attractive [23]. Moreover, Soh et al. found that dental students and laypersons were more tolerant of a male profile with a retrusive mandible than were dental professionals, and all groups were more tolerant of bimaxillary protrusion in women than in men [28].

In contrast Hakan et al. found that among the Turkish population both genders with orthognathic profile was the most attractive profile whereas prognathic maxilla and retrognathic mandible with a convex profile is the least preferred one [29].

\section{Facial profile self-awareness}

This study reports that students were overall aware of their profiles, unlike Phillips et al. which concluded that participants were not aware of their facial profile [30].

In contrast Soh et al. concluded that the perception of female profiles when compared by all 3 groups; dental professionals, dental students, and laypersons was highly and significantly correlated. Only the perception of male esthetics by dental students and laypersons was not significantly correlated with dental professionals [31]. Moreover, Amjad et al. found that there were low levels of self awareness amongst the laypersons including both genders in United Arab Emirates [23].

This variation in results among different population can be partially attributed to the sample size, ethnic background as well as the general awareness of the individuals towards the facial profile.

\section{Conclusion}

- The straight facial profile was perceived to be highly attractive by both male and female students.

- Male facial profiles with protrusive maxilla and a female profile with bimaxillary protrusion were considered the least attractive.

- In relation to self awareness students were generally able to characterize their own profile. Yet female students were slightly more self conscious than males.

\section{Recommendations}

In the future, a larger sample size is recommended to be studied with a more diverse age range and at different areas in Sudan in order to have an overview on the perception and self awareness of facial profile among the general Sudanese population, hoping this results can act as a guideline for orthodontists and orthodontic surgeons for treatment planning of an esthetically pleasing facial profile.

\section{References}

1. Riggio RE, Cole EJ (1991) Beauty is more than skin deep: components of attractiveness. Basic Applied Psychology 12: 423-429.

2. Nguyen DD, Turley PK (1998) Changes in the Caucasian male facial profile as depicted in fashion magazines during the twentieth century. Am J Orthod Dentofacial Orthop 114: 208-217. [Crossref]

3. Silva NCF, Aquino ERB, Mello KCFR, Mattos JNR (2011) Orthodontists and laypersons perception of mandibular asymmetries. Dental Press J Orthod 16: 38.e1-8.

4. Borzabadi-Farahani A (2012) A review of the evidence supporting the aesthetic orthodontic treatment need indices. Prog Orthod 13: 304-313. [Crossref]

5. Martin JG (1964) Racial Ethnocentrismand Judgmentof Beauty. J Soc Psychol 63: 5963. [Crossref]

6. Lew KK, Soh G, Loh E (1992) Ranking of facial profiles among Asians. J Esthet Dent 4: 128-130. [Crossref]

7. Cochrane SM, Cunningham SJ, Hunt NP (1999) A comparison of the perception of facial profile by the general public and 3 groups of clinicians. Int J Adult Orthodon Orthognath Surg 14: 291-295. [Crossref]

8. Mikawa M, Iida M, Saito S (2004) Clinical and statistical study on jaw deformity patients in the orthodontic department, Showa University Dental Hospital. Orthod Waves 63: 49-59.

9. Tufekci E, Jahangiri A, Lindauer SJ (2008) Perception of profile among laypeople, dental students and orthodontic patients. Angle Orthod 78: 983-987. [Crossref]

10. Spyropoulos MN, Halazonetis DJ (2001) Significance of the soft tissue profile on facial esthetics. Am J Orthod Dentofacial Orthop 119: 464-471. [Crossref]

11. Bishara SE, Jorgensen GJ, Jakobsen JR (1995) Changes in facial dimensions assessed from lateral and frontal photographs. Part I - Methodology. Am J Orthod Dentofacial Orthop 108: 389-393. [Crossref]

12. Ferrario VF, Sforza C, Miani A, Tartaglia G (1993) Craniofacialmorphometry by photographic evaluations. Am J Orthod Dentofacial Orthop 103: 327-337. [Crossref]

13. Imara de Almeida Castro M, Ana Paula Lazzari Marques P, Keila Rodrigues C, Ricardo M (2012) Study of face pleasantness using facial analysis in standardized frontal photographs. Dental Press Journal of Orthodontics 17: 24-34.

14. Borelli C, Berneburg M (2010) Beauty lies in the eye of the beholder? Aspects of beauty and attractiveness. $J$ Dtsch Dermatol Ges 8: 326-330. [Crossref]

15. Borman H, Ozgür F, Gürsu G (1999) Evaluation of soft-tissue morphology of the face in 1,050 young adults. Ann Plast Surg 42: 280-288. [Crossref]

16. Arnett GW, Jelic JS, Kim J, Cummings DR, Beress A, et al. (1999) Soft tissue cephalometric analysis: diagnosis and treatment planning of dentofacial deformity. $\mathrm{Am}$ J Orthod Dentofacial Orthop 116: 239-253. [Crossref]

17. Vegter F, Hage JJ (2000) Clinical anthropometry and canons of the face in historical perspective. Plast Reconstr Surg 106: 1090-1096. [Crossref]

18. Davidson L (2010) Africa adorned: body image and symbols of physical beauty. $J$ Am Acad Psychoanal Dyn Psychiatry 38: 255-259. [Crossref]

19. Romm S (1987) Art, love, and facial beauty. Clin Plast Surg 14: 579-583. [Crossref]

20. Romm S (1989) The changing face of beauty. Aesthetic Plast Surg 13: 91-98. [Crossref]

21. Morosini IAC, Peron APLM, Correia KR, Moresca R (2012) Study of face pleasantness using facial analysis in standardized frontal photographs. Dental Press J Orthod 17: 24-34.

22. Johnston C, Hunt O, Burden D, Stevenson M, Hepper P (2010) Self-perception of dentofacial attractiveness among patients requiring orthognathic surgery. Angle Orthod 80: 361-366. [Crossref]

23. Al Taki A, Guidoum A (2014) Facial profile preferences, self-awareness and perception among groups of people in the United Arab Emirates. J Orthod Sci 3: 55-61. [Crossref]

24. Shimogaki SK (2007) Position of the lips and facial profile: preferences of orthodontists versus lay people Student Scholar Archive. Paper 829.

25. Wang YY, Guo CC, Zhou C, Fan ML, Wang WC, et al. (2012) Investigation on facial profile preferences of orthodontic patients. Shanghai Kou Qiang Yi Xue 21: 668-672. [Crossref]

26. Abu Arqoub SH, Al-Khateeb SN (2014) Perception of facial profile attractiveness 
of different anterio-posterior and vertical proportions. Eur J Orthod 33: 103-111. [Crossref]

27. Mejia-Maidl M, Evans CA, Viana G, Anderson NK, Giddon DB (2005) Preferences for facial profiles between Mexican Americans and Caucasians. Angle Orthod 75: 953 958. [Crossref]

28. Soh J, Chew MT, Wong HB (2007) An Asian community's perspective on facial profile attractiveness. Community Dent Oral Epidemiol 35: 18-24. [Crossref]
29. Türkkahraman H, Gökalp H (2003) Facial Profile Preferences among Various Layers of Turkish Population. Angle Orthod 74: 640-647. [Crossref]

30. Phillips C, Griffin T, Bennett E (1995) Perception of facial attractiveness by patients, peers, and professionals. Int J Adult Orthodon Orthognath Surg 10: 127-135. [Crossref]

31. Soh J, Chew MT, Wong HB (2005) A comparative assessment of the perception of Chinese facial profile esthetics. Am J Orthod Dentofacial Orthop 127: 692-699. [Crossref]

Copyright: (C2015 Ali LS. This is an open-access article distributed under the terms of the Creative Commons Attribution License, which permits unrestricted use, distribution, and reproduction in any medium, provided the original author and source are credited. 